\title{
Os Estados Unidos pós 11 de setembro de 2001: implicações para a ordem mundial e para o Brasil
}

\section{RUBENS ANTÔNIO BARBOSA*}

Que implicações os ataques ao Pentágono e ao World Trade Center (WTC) apresentam para os Estados Unidos e para as relações internacionais? Quais seriam suas conseqüências para a ordem mundial deste início do século XXI? Cabe com efeito a pergunta sobre se os eventos de 11 de setembro teriam, de fato, transformado a ordem global a ponto de constituir um divisor de águas na política mundial.

Os eventos de 11 de setembro de 2001 foram e têm sido apresentados como um momento de ruptura no sistema das relações internacionais, ou pelo menos como um elemento novo na agenda da política mundial, ponto definidor de uma nova relação dos Estados Unidos com a ordem global, em grande medida dominada por esse mesmo país. O Brasil, ainda que situado em área relativamente imune à ação do terrorismo de base fundamentalista, também passou a sofrer as conseqüências da situação criada a partir da reação dos EUA a esses ataques, como pretendo discutir neste ensaio.

Uma análise preliminar e introdutória aos problemas do 11 de setembro e de seu status na política americana e mundial confirmaria que, como quaisquer outros fenômenos históricos, estes possuem, ao mesmo tempo, elementos de ruptura e de continuidade. O mundo pós-11 de setembro não mudou, mas a agenda da política mundial modificou-se, não tanto pela ação em si dos terroristas como pela demonstração da vontade de poder da maior potência de nossa época.

O presente texto pretende: (a) colocar os ataques terroristas no contexto da ordem mundial atual; (b) discutir as reações dos EUA no imediato seguimento dos eventos, examinando seu impacto específico na economia, na política externa e na área de segurança; (c) considerar os efeitos dos ataques do ponto de vista da ordem internacional, em termos de rupturas e continuidades; (d) examinar mais de perto sua interação com o processo em curso de globalização, fenômeno claramente associado, para a maior parte dos observadores, à presença e ação dos EUA no plano mundial; (e) discutir, finalmente, as implicações desses fatos e processos para o Brasil. 


\section{O contexto do 11 de setembro: novo "Império”, novos “bárbaros”}

Os atentados de 11 de setembro ocorrem no momento em que os EUA, superados os obstáculos da Guerra Fria e somado o crescimento acumulado ao longo dos últimos 10 anos de boom econômico, atingem a plena maturidade de seu poderio e ocupam um lugar no panteão das potências mundiais só comparável à Roma imperial.

Michael Hardt e Antonio Negri ${ }^{1}$, ao descrever a natureza e o alcance do poder dos EUA na atualidade, apontam para a natural (e quase automática) identificação desse país como a autoridade definitiva a reger o processo de globalização e a própria ordem mundial. Segundo os autores, o exercício de poder dos EUA se dá no contexto do que denominam o "Império", conceito definido como a nova forma global de economia, que não deve ser confundido com a desgastada noção de imperialismo. ${ }^{2}$ O Império não dispõe de um contorno territorial definido, na medida em que constitui, ele mesmo, um processo de “desterritorialização”, que incorpora gradualmente o mundo inteiro dentro de suas fronteiras abertas. $\mathrm{O}$ poder exercido pelo Império não tem limites e representa um regime que, efetivamente, abrange a totalidade do espaço. O Império governa todo o mundo “civilizado" (conceito que, neste contexto, tende a confundir-se com "globalizado"), não como um regime histórico nascido da conquista, mas como uma ordem que, na realidade, suspende a história, determinando, dessa forma, o estado de coisas

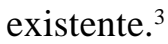

Os EUA - “país mais poderoso desde Roma”, segundo Joseph $\mathrm{Nye}^{4}$-, a única superpotência da atualidade, ocupam posição central nessa nova ordem capitalista "imperial”. Seu espaço territorial, que não se confunde com as abertas fronteiras do Império capitalista, é o centro nervoso - dinâmico - de onde emanam e para onde convergem os fluxos dessa nova ordem econômica. Atores privilegiados, os EUA são também os “ordenadores” ou "regentes” do Império, dele extraindo os maiores dividendos. Natural, nesse contexto, que os EUA, império dentro do "Império", tenham logrado alçar-se, nos últimos anos, a uma situação de incontrastável superioridade em todos os campos do poder: econômico, tecnológico e militar. O poderio político, que nada mais é do que o exercício dessa superioridade no campo da relação entre os Estados, decorre direta e naturalmente dessa situação, que os EUA procurarão manter por todos os meios. ${ }^{5}$

Do ponto de vista econômico e financeiro, a hegemonia dos EUA revelase claramente no diferencial de poder entre os principais atores globais: os EUA representam cerca de $31 \%$ do produto interno bruto mundial (mais do que os quatro seguintes - Japão, Alemanha, Inglaterra e França - juntos), são os maiores importadores e exportadores do planeta (17\% das importações mundiais de bens e 8\% das de serviços; $13 \%$ das exportações mundiais de bens e 18\% das de serviços, em dados de 1998), os maiores produtores de bens industriais (cerca de $25 \%$ da 
produção mundial), os maiores investidores e também os maiores recipientes de investimentos diretos, de longe o principal produtor e exportados de filmes e de programas de televisão no mundo. ${ }^{6}$ Por dez anos (1991-2000), a economia norteamericana cresceu em média 3\% (no mesmo período, a taxa média de crescimento do PIB japonês foi de cerca de 1,5\% e o da União Européia de menos de $2 \%$ ).

O mais significativo, no entanto, é que esse impressionante desempenho foi sustentado, entre outros aspectos, por uma verdadeira (e, até certo ponto, genuinamente americana) "nova revolução industrial” que, através dos avanços tecnológicos alcançados nas áreas da comunicação e do conhecimento (Internet, por exemplo), gerou transformações sem paralelo na operação das empresas americanas. Esse novo e inventivo modo de produção, aplicado com notável persistência, coerência e sucesso a toda a atividade produtiva (e, como veremos a seguir, à própria “arte da guerra”) americana, é o principal responsável pela evolução sem precedentes de seu poderio, que elevou os EUA à condição de única verdadeira superpotência. ${ }^{7}$

A superioridade tecnológica e militar dos EUA é igualmente evidente e revela-se num simples fato: os EUA são o único ator global da história da humanidade que consegue projetar poder militar simultaneamente em diferentes terrenos estratégicos em pontos distantes de seu próprio território (o orçamento de defesa dos EUA é superior à soma dos orçamentos militares dos seguintes 15 aliados ou competidores estratégicos, a começar pela Rússia, China e os principais países da OTAN).

O contraste entre o know-how superior dos EUA em "levar a guerra" ao resto do mundo e o poder militar apenas relativo dos demais competidores estratégicos, deve-se, além do peso específico do primeiro no campo econômico e tecnológico, à aplicação dos mesmos modelos organizacionais e produtivos que já tinham determinado a preeminência de seu tipo específico de capitalismo no final do século XIX e início do século XX. Na origem da defasagem de poder de fogo entre os EUA e o resto do mundo encontrar-se-ia, portanto, não apenas a simples capacitação tecnológica - que poderia ser eventualmente suprida no caso dos europeus ou mesmo no caso das duas grandes economias em transição para o capitalismo - mas uma organização superior de administração militar, que consegue aproveitar ao máximo os ganhos de produtividade revelados em um longo ciclo de crescimento econômico baseado nas virtudes inovadoras da "nova economia" (informação, comunicações, processamento digital de insumos aplicados a novos tipos de armas).

Tal disparidade - que pode ser classificada como propriamente "estrutural", ou seja, não simplesmente quantitativa - não tem precedentes históricos provavelmente desde os tempos da Pax Romana. O alegado poder naval absoluto da Royal Navy, nos tempos áureos da Pax Britannica, não guarda senão uma pálida relação com a presente situação de domínio incontrastável das forças armadas dos EUA. 
A ação contra o World Trade Center e o Pentágono, centros nevrálgicos (e simbólicos) do poderio americano, vai buscar suas origens no outro lado do fenômeno analisado por Hardt e Negri: o território dos excluídos do Império - os “bárbaros” (ou “novos bárbaros”, na opinião de Jean Christophe Ruffin) ${ }^{8}$. As motivações por trás dos ataques remetem, de uma maneira ou de outra, à essência do fenômeno terrorista e a suas conseqüências: a exclusão de boa parte do mundo da prosperidade do Império (e a instabilidade política, a privação econômica e social dela decorrentes); a resistência a integrar-se à globalização (o choque "civilizacional”, as bases do fundamentalismo islâmico que rejeitam aspectos importantes dessa globalização); a arrogância imperial (o exercício político do poder americano, a política externa dos EUA para o Oriente Médio, a aliança com Israel, a "ocupação" da Arábia Saudita).

A reação dos EUA aos ataques foi, ela também, ditada pela situação particular que ocupa aquele país no centro do Império global e pela natureza especial dos ataques, que desafiaram essa posição: uma resposta feita ao mesmo tempo de unilateralismo, de intervencionismo e do eventual e bem medido ("à la carte”) ${ }^{9}$ apelo ao multilateralismo e à cooperação seletiva, sob a forma de alianças e parcerias.

Contrariamente a conflitos anteriores (Guerra do Golfo, por exemplo), em que os EUA buscaram legitimar sua ação intervencionista através de alianças estratégicas com outros países ou entidades multilaterais, o 11 de setembro, ataque direto à própria essência do "ser” americano, trouxe, na percepção de que constituía uma luta entre o bem e o mal, elementos que legitimavam uma reação imediata e unilateral. A rede de apoio e solidariedade que rapidamente se construiu em torno dos EUA não foi, nesse sentido, propriamente reivindicada por aquele país, mas sim esperada como fato natural. As declarações do Presidente Bush a esse respeito (“quem não estiver com os EUA estarão contra”) são a melhor tradução dessa expectativa: em um embate como o que se delineava, os países que não se encontravam sob o império do bem só poderiam estar do lado do mal. Nesse sentido, a construção de alianças pelos EUA para responder ao 11 de setembro corresponde mais a um ato de "corroboração" de seu sistema de valores, do qual esperavam que os demais membros do "Império" comungassem, do que propriamente à preocupação de legitimar ou apoiar ações contra seus atacantes (que também existiu, é bem verdade, no caso de países como o Paquistão ou a Índia, situados à margem do "Império").

\section{O 11 de setembro e a reação dos EUA: velhos demônios, novas prioridades}

Os ataques ao World Trade Center e ao Pentágono foram recebidos com surpresa e revolta pelo Governo e pelo povo norte-americanos. Washington fora 
atacada pela última vez em 1812, quando, na guerra anglo-americana, os ingleses incendiaram a Casa Branca.

O poderio incontestado dos Estados Unidos depois da Guerra Fria tornou arraigado o sentimento de invulnerabilidade do pais à violência que cresce e se desenvolve em outras regiões. Tanto maior foi, nesse contexto, o impacto do $11 \mathrm{de}$ setembro sobre a psique americana, ao representar, na "descoberta" da vulnerabilidade, um choque nunca antes experimentado e a sensação de que o país nunca mais seria o mesmo. A rapidez e a dimensão da resposta aos ataques, considerados desde o início como "atos de guerra", dão a dimensão exata da comoção por eles provocada.

Uma comoção que levou, naturalmente, à comparação do 11 de setembro ao ocorrido em Pearl Harbor em dezembro de 1941, na medida em que ambos constituiriam um ataque direto (e inédito) ao território e ao poderio militar dos EUA. Esta comparação é, a meu ver, discutível, de vez que Pearl Harbor representou uma operação militar, desfechada por um competidor militar, contra um objetivo militar, em um contexto de guerra mundial. O 11 de setembro é fato de outra natureza, que pertence mais à família dos atentados como o de Oklahoma (que foi também um ataque terrorista "contra o estado americano", golpeando civis inocentes de maneira errática), com a distinção fundamental de que se apresenta como uma reação direta a aspectos "profanos" da política externa dos EUA no Oriente Médio, como a ocupação da "terra sagrada” (Arábia Saudita) ou o apoio aos inimigos do Islã (Israel), conforme pronunciamento de Bin Laden.

A resposta americana aos ataques comporta traços igualmente ideológicos: apresentada como uma reação de autodefesa interna e externa, ela é legitimada pela percepção de que os atentados constituíram um ataque ao bem pelo mal (uma simplificação quase "fundamentalista”), tendo as causas mais profundas do fenômeno do terrorismo sido pouco ou nada discutidas (política externa dos EUA para o Oriente Médio, pobreza e falta de democracia em países islâmicos etc).

Nessa resposta, que afetará a economia e as políticas interna, externa e de defesa dos EUA, definir-se-ão claramente as novas prioridades do governo americano e o terrorismo e a segurança passarão a pautar as novas relações do país com os demais atores do sistema internacional. ${ }^{10}$ As conseqüências imediatas dos ataques e dessa reação são analisadas sucintamente a seguir. Outros efeitos do 11 de setembro, de natureza mais sistêmica (ordem mundial, globalização), serão considerados em seção à parte.

\section{Economia:}

Do ponto de vista econômico, temeu-se que o ciclo recessivo que já vinha enfrentando a economia americana desde o início de 2001 fosse agravado pela crise que os atentados provocaram em diversos setores: transportes aéreos, turismo, 
seguros, intermediação financeira etc. Na realidade, as conseqüências econômicas do terror revelaram-se menos graves do que havia sido imaginado, com escassas repercussões globais, ainda que efeitos setoriais importantes, em especial nas indústrias ou serviços mais diretamente vinculados ao centro do capitalismo financeiro nova-iorquino.

Na outra ponta do processo, os atentados podem ter servido para justificar politicamente uma nova série de gastos militares que representarão uma notável impulsão em determinadas áreas ligadas ao chamado "complexo industrial-militar", assim como às indústrias e serviços de segurança e de monitoramento eletrônico, da mesma forma como o anterior "império do mal” da era Reagan gerou um conjunto de gastos orçamentários que alguns observadores tinham identificado à época como "keynesianismo militar".

De fato, haverá uma sensível pressão para o investimento e a inovação em todas as áreas consideradas como estratégicas, assim como, secundariamente, em setores como o de saúde pública, posto à prova pelo episódio do antraz. O próprio programa de capacitação missilística e de prevenção de ataques-surpresa, patrocinado pelos republicanos sob o nome de "National Missile Defense" reedição mais modesta da "Strategic Defense Initiative" da era Reagan -, cujos dias pareciam contados nesse novo cenário de luta contra o terrorismo, deverá ser preservado pela atual Administração.

Ainda na área econômica, tornou-se evidente que os atentados estimularam o surgimento de um novo ambiente regulatório e normativo no campo das transações financeiras, com a aceleração dos esforços de cooperação internacional nesse terreno, algo que era necessário para combater práticas nem sempre imediatamente associadas ao terrorismo, como a corrupção, a lavagem de dinheiro, os fluxos utilizados pelas redes de narcotraficantes e outros ilícitos financeiros de caráter mais político.

\section{Segurança:}

No campo da segurança, a defesa interna e a vigilância nas fronteiras e aeroportos tendem a assumir espaço relevante na agenda americana e, por extensão, na da cooperação política internacional.

Na frente interna, o grande debate nos EUA refere-se aos conflitos que medidas de controle de tipo intrusivo podem representar para as chamadas liberdades civis, algo relevante num país que ostenta orgulho por não possuir nenhum sistema nacional de identificação pessoal e cujos cidadãos exibem uma natural desconfiança em relação ao Estado federal (ou qualquer estado, para os muitos libertários, que são legião em suas várias vertentes, de direita, de esquerda, de caráter civil ou religioso).

A esse debate, deve-se acrescentar as reações (é bem verdade que mais brandas) suscitadas pela aprovação, a toque de caixa, de um novo plano nacional 
de segurança que, entre outras duras medidas, prevê a criação de organismo responsável pela defesa civil (Homeland Defense), de um corpo de defesa militar voltado para a própria América do Norte, o recurso a tribunais militares - que reduzem consideravelmente os instrumentos de defesa dos réus - para julgamentos de estrangeiros acusados de crimes de terrorismo, bem como a adoção de medidas “especiais” para encarceramento, pelo INS (serviço nacional de migrações), de imigrantes em situação suspeita - contam-se às centenas os casos de estrangeiros residentes detidos durante meses pelo INS, incomunicáveis, com base em frágeis indícios.

Na frente externa, a pressão americana em matéria de segurança se exerce sobre os demais países no sentido da coordenação de ações de polícia e inteligência, o que nem sempre é feito de maneira voluntária ou de modo amplo como gostariam as autoridades americanas dessas áreas (FBI e CIA). Em todo caso, as bases de dados de todos os sistemas policiais dos países envolvidos de perto ou de longe na luta contra o terrorismo serão chamadas a cooperar, voluntária ou "involuntariamente", com essas mesmas autoridades.

Adicionalmente, tem aumentado de modo significativo, em especial após a conclusão da chamada "fase um" da guerra contra o terrorismo no Afeganistão (Operação Anaconda), a pressão dos EUA em relação ao controle de armas de destruição em massa. O tema vem paulatinamente sendo incorporado à doutrina Bush em matéria de segurança ${ }^{11}$ e tem servido de justificativa para as ameaças e preparativos para uma eventual intervenção no Iraque.

\section{Política Externa:}

Os atentados recolocaram na agenda americana a prioridade dos temas de política externa, no momento em que o debate interno vinha sendo ocupado exclusivamente por temas como as leis de financiamento político, o reforço do sistema nacional de educação, a reforma do sistema de seguridade social, a estrutura do fornecimento energético ou a regulação ambiental. Fiel à percepção maniqueista de que os EUA (e o mundo civilizado - o Império de Hardt e Negri) - travam uma luta do bem contra o mal ${ }^{12}$, o Presidente George W. Bush não tardou em dar o tom da disposição americana, ao eleger um "eixo do mal” (Coréia do Norte, Irã e Iraque e, posteriormente, a Síria) e proclamar, repetidas vezes, que quem não estivesse com os EUA estaria contra ele.

O debate interno sobre a política externa que melhor convém aos EUA tem colocado em campos opostos os defensores de uma auto-suficiência unilateralista (que tendem a predominar) e os que advogam a integração dos EUA nas regras multilaterais da comunidade internacional. ${ }^{13}$

As ações americanas no campo político, militar, econômico e diplomático, que se seguiram aos ataques, refletem essa ambivalência, deixando transparecer 
uma tendência crescentemente unilateral temperada pela busca de entendimentos e alianças pontuais (“à la carte”) com a comunidade internacional em fóruns específicos, como as Nações Unidas e a OTAN. ${ }^{14}$

O relacionamento entre os EUA e as instituições multilaterais passa, nesse contexto, por uma fase de maiores conflitos. O 11 de setembro acentuou uma tendência que já era visível na relação do governo Bush com vários organismos e acordos internacionais, marcada pela preocupação com a preeminência do interesse nacional norte-americano e a aversão em aceitar constrangimentos em áreas consideradas como sensíveis do ponto de vista de Washington. ${ }^{15}$

Exemplos marcantes disso são as posições do governo americano em relação ao Tribunal Penal Internacional, ao Protocolo de Quioto e aos entendimentos sobre desarmamento (recusa do Protocolo de Verificação da Convenção sobre Proibição das Armas Biológicas, do Tratado de Proibição de Testes NuclearesCTBT, do Tratado sobre Mísseis Balísticos-ABM e do Protocolo de Montreal sobre Minas Terrestres). Nessa mesma linha, a avassaladora pressão americana para o afastamento do diretor-geral da Organização para a Proscrição de Armas Químicas (OPAQ), diplomata brasileiro, do Presidente do Comitê Intergovernamental de Mudança de Clima (IPCC) assim como a renúncia da Alta Comissária de Direitos Humanos, Mary Robinson, por alegada interferência dos EUA são exemplos importantes do conflito de interesses entre os EUA e os organismos multilaterais. ${ }^{16}$

Nesse contexto de crescente unilateralismo, temperado com multilateralismo seletivo, a aceitação da administração americana em encarar tarefas de "nation building” - pelo menos no caso do Afeganistão - assim como de considerar o incremento real de dotações atribuídas a título de ajuda oficial ao desenvolvimento, são concessões tópicas que não modificam as ênfases principais da política externa norte-americana. Essa última decisão, anunciada em pronunciamento do Presidente Bush em Monterrey (Cúpula sobre Financiamento ao Desenvolvimento), vem temperar as manifestações mais duras presentes em discursos anteriores, como o do "State of the Union", em que foi cunhada a controvertida expressão "eixo do mal”, foco da prioridade contra o terrorismo.

A política externa americana para o Oriente Médio, item de fundamental importância na nova agenda internacional, é, ela também, marcada pela oscilação entre unilateralismo e multilateralismo. Chama a atenção, por exemplo, a aprovação, com aval americano, da Resolução 1397 do Conselho de Segurança as Nações Unidas sobre a questão palestina, depois de anos de ação persistente e inflexível dos EUA no sentido de bloquear qualquer intervenção efetiva do CSNU no tratamento dessa questão. Pela primeira vez na história do Conselho, a menção a um "Estado Palestino" figurou numa resolução desse órgão, ainda que não se vislumbre que conseqüência prática poderá advir dessa manifestação. Mesmo 
porque, fiel à ambivalência de sua posição (a qual, no caso do conflito israelopalestino tende a se acentuar pela presença da questão do terrorismo e pela sensibilidade que desperta nos eleitores americanos), o governo dos EUA, ao tempo em que aprovava a inédita Resolução, dava apoio tácito à política israelense de ampliar sua presença militar nos territórios sob controle da Autoridade Nacional Palestina, posição que compromete ainda mais o processo de paz na região.

Outro vetor de um possível agravamento da situação no Oriente Médio, a questão da mudança de regime no Iraque - na qual a perspectiva de liquidação de uma "hipoteca” herdada do governo George Bush pai pode levar a uma ruptura na coalizão de forças ocidentais - é tema sobre o qual correntes opostas dentro da própria Administração americana se dividem entre intervencionismo unilateral e concertação multilateral, com clara vantagem, até o momento, para a primeira tendência (que tem fundamentado argumentos pró-intervenção na necessidade urgente de controle sobre uma eventual produção iraquiana de armas de destruição em massa - químicas e biológicas).

No campo militar, o desdobramento mais importante dos acontecimentos de setembro terá sido a intenção (não oficialmente declarada) da administração dos EUA de introduzir uma nova concepção em sua doutrina estratégica para utilização da arma nuclear. Passou-se da doutrina da dissuasão retaliatória (consubstanciada na hipótese MAD, ou seja, a "mutually assured destruction”) para uma de "dissuasão ofensiva", que não excluiria a utilização da arma atômica em primeira instância mesmo na ausência de uma clara ameaça nuclear por parte de outro estado ou grupo (mas em presença de uma possível utilização de outras armas de destruição em massa, como poderiam ser os vetores químicos e biológicos). ${ }^{17}$ Observadores já mencionaram o perigo potencial dessa nova concepção para a própria segurança e estabilidade mundiais, inclusive do ponto de vista da não-proliferação e do desarmamento, uma vez que ela vem associada à indicação dos possíveis contendores nesse terreno, um conjunto de sete países que inclui os chamados “rogue states”, mas também grandes potências como Rússia e China.

Foi, igualmente, ressuscitado o debate em torno do conceito de "armas nucleares utilizáveis” (“usable nukes”) que ganhou mais força após os acontecimentos de 11 de setembro e a ação militar no Afeganistão. O governo Bush afirmou que, em caso de ataque, nenhuma opção de resposta seria excluída. O Congresso, por seu lado, incluiu na "Defense Authorization Bill”, em 2001, solicitação de que o Departamento de Energia e o Departamento de Defesa levassem a cabo novos estudos sobre o uso de armas nucleares subquilotônicas. O debate sobre "usable nukes" modifica de forma substancial o conceito de dissuasão ao incorporar uma vertente ofensiva que terá, sem dúvida, impacto importante nos debates sobre não proliferação. 


\section{Efeitos do 11 de setembro sobre a ordem internacional: rupturas e continuidades}

De que maneira os eventos de 11 de setembro afetaram a ordem mundial? Os atentados de 11 de setembro trouxeram o item "terrorismo" para o centro da agenda internacional ${ }^{18}$, onde ele deverá permanecer no futuro previsível. O tema poderá eventualmente deixar a primeira posição nessa agenda, mas permanecerá subjacente ao planejamento cooperativo no terreno da segurança, o que deve ser considerado como dado adquirido na formulação da política externa de todos os países.

Não parece, no entanto, que o 11 de setembro tenha provocado o surgimento de uma "nova ordem mundial”. A situação internacional tem sido descrita, desde o fim da Guerra Fria, como "unipolar”, "multipolar” ${ }^{19}$ e "uni-multipolar”. ${ }^{20}$ Subsiste a mesma "velha" ordem, ainda que com uma nova agenda e um novo conjunto de prioridades. Uma eventual e hipotética "nova ordem” dependeria, não de qualquer mudança introduzida pelo terrorismo ou pela luta contra ele, mas basicamente de um novo arranjo global entre as principais potências militares, o que se dá, normalmente, como resultado de mudanças estruturais de longa duração.

Nada mudou no poder relativo e nas posições ocupadas no cenário internacional pela União Européia, Japão, China e Rússia. O que se alterou foram as prioridades, próprias ou relativas, desses atores principais em seus jogos táticos respectivos de alianças e parcerias. Antes mesmo que os EUA reagissem a pretexto de autodefesa e iniciassem sua guerra ampliada contra o terrorismo - incluindo aqui estados e governos - algumas mudanças se tornaram perceptíveis: a Rússia de Putin, por exemplo, encontrou neste novo cenário contexto ideal para uma aproximação dos países da OTAN e de seu decision-making process. Esse movimento, que não atende necessariamente ao objetivo de coordenação de políticas anti-terror, poderá oferecer à Rússia ocasião extremamente propícia para uma redefinição de suas relações globais com o Ocidente. Osama Bin Laden conseguiu realizar o inimaginável antes de 11 de setembro: trazer a Rússia para o coração da OTAN (não me refiro aqui, obviamente, a uma aceitação formal na aliança que, de toda forma, depende mais de sua evolução política interna do que aspectos militares em si). A Índia, por razões diferentes, está gradualmente ascendendo a nível equivalente de entendimento.

O que está mudando é a relação dos EUA com o mundo. O 11 de setembro e a alteração de prioridades da agenda mundial levaram os EUA ampliar o número de "parcerias" em todo o planeta. O país, que continua contando com o mesmo número de aliados de antes dos ataques (a Grã-Bretanha, Israel e os países da OTAN, basicamente), multiplicou a quantidade de parceiros de uma forma que dificilmente se poderia esperar através do "world politics as usual”. A política mundial "normal” não teria provavelmente nunca levado a Rússia, a China e outros 
países, em verdadeira reversão de alianças, a se declararem dispostos a cooperar com os EUA como atualmente. Vários outros países, da mesma forma, sentiram que a direção dos ventos mudou significativamente (Síria e Irã, para mencionar apenas dois, mais próximos do teatro de operações) e passaram a se comportar em conformidade com os novos tempos.

Em conseqüência disso, os EUA, que elevaram o terrorismo à mais alta prioridade em sua política externa, vão influenciar, no futuro previsível, os esforços internacionais em prol da coordenação em matéria de segurança, na medida em que vão continuar pressionando os demais estados e as Nações Unidas a atuar decisivamente contra os grupos terroristas e os estados que os abrigam.

Em suma, a nova "agenda terrorista" mudou o jogo das coalizões e trouxe mais parceiros ao tabuleiro estratégico dos EUA, não tendo mudado, entretanto, a natureza ou a estrutura das relações internacionais. A "Pax Americana” está instaurada e deverá permanecer como um referencial para as próximas décadas, restando saber até que ponto contribuirá para assegurar a manutenção da paz e da

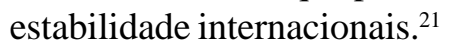

\section{O 11 de setembro e a globalização}

Ainda parece cedo para chegar a conclusões sobre que efeitos o 11 de setembro terá sobre a globalização. É fato, no entanto, que os ataques ao WTC e ao Pentágono, que têm origem em uma clara rejeição a valores e desdobramentos desse fenômeno (vale frisar que os dois alvos eram, respectivamente, os maiores símbolos do poderio econômico e militar da maior potência do mundo globalizado), têm afetado, através das mudanças que provocaram na condução da política externa americana - e da reação a essas mudanças -, o seu desenvolvimento.

O aparente sucesso da globalização nos planos econômico e tecnológico tem contrastado, ultimamente, com dificuldades encontradas na tentativa de impulsionar esse mesmo processo no plano jurídico, em grande medida devido à ação obstrutora dos EUA (uma tendência que tem se tornado mais visível depois dos atentados do 11 de setembro). A superestrutura política do direito internacional público vem sendo penosamente construída por atores - Estados, organizações, indivíduos - engajados na tarefa de substituir o direito da força pela força do Direito e a solução pacífica das controvérsias pela justiça algo arbitrária dos mais fortes.

Essa lenta construção do multilateralismo contemporâneo vem sendo ameaçada por atitudes sucessivas dos EUA, especialmente após o 11 de setembro, que confirmam uma relutância de princípio e uma recusa de fato em assumir novos compromissos que redundariam, direta ou indiretamente, na diminuição da margem de liberdade alocada aos EUA como grande potência que aceita o Direito Internacional na medida em que o seu interesse nacional não é afetado. 
Também no terreno comercial, o 11 de setembro tem acentuado frustrações acumuladas em decorrência de atitudes da administração americana que, na prática, desmentem fundamentos da globalização, como o livre comércio. Prejuízos reais para os principais parceiros dos EUA, a começar pelo próprio Brasil, são o resultado. Bastaria citar, por exemplo, a visível dificuldade para a aprovação de uma autorização congressual para negociações comerciais multilaterais - agora chamada de Trade Promotion Authority - ou o contorcionismo legal demonstrado na introdução de salvaguardas para o setor do aço, para constatar a imensa distância entre a retórica do livre comércio e a dura realidade do protecionismo americano.

Nos planos regional ou bilateral, ou ainda em escala simplesmente “unilateral”, abundam os exemplos dessa vontade americana de lograr uma espécie de "livre comércio indolor", no qual apenas os setores nos quais os EUA são mais competitivos seriam passíveis de discussão e acordos de abertura.

É fato que as práticas abusivas de protecionismo explícito e de subvencionismo prejudicial aos interesses de países como o Brasil não datam da presente Administração e devem continuar num futuro ainda indefinido, mas é também verdade que os eventos de 11 de setembro animaram um Congresso, já normalmente engajado na defesa dos chamados "interesses especiais", a comprometer-se ainda mais com a proteção de setores pouco competitivos e historicamente insulados da oferta estrangeira.

As contradições na área comercial reproduzem-se também na área financeira, sem que se saiba quais serão as novas prioridades para as organizações de Bretton Woods em casos de crises agudas, como a experimentada pela Argentina, que aparentemente foi entregue à sua própria sorte, parcialmente em função do deslocamento de prioridades na agenda externa americana, que motivou certo "alheamento" em relação a temas menos centrais.

Esse mesmo deslocamento tem feito com que países considerados prioritários na luta contra o terrorismo sejam recompensados com esquemas especiais no plano bilateral, no foro restrito do Clube de Paris ou nos esquemas de crédito contingencial do FMI ou dos bancos multilaterais, o que não ocorre em casos colocados numa lista secundária. Mesmo o recente anúncio de aumento nas alocações oficiais para ajuda ao desenvolvimento e a intenção de transformar o sistema de empréstimos em doações monitorados segundo o grau de "good governance" chocam-se com as evidências, repetida e insistentemente avançadas por economistas, segundo as quais a melhor forma de ajuda ao desenvolvimento é a liberalização comercial para facilitar o acesso dos países pobres aos mercados avançados e o desmantelamento da panóplia de medidas protecionistas mantidas nestes últimos. A ênfase nas doações, por sua vez, atuará em detrimento de países médios como o Brasil, que não mais se beneficiam de operações concessionais e que passarão a enfrentar restrições ou custos adicionais em seus projetos sustentados parcialmente com financiamentos multilaterais. 


\section{O Brasil e a nova ordem mundial pós-11 de setembro}

O impacto dos ataques terroristas no Brasil e na América do Sul - regiões que são, em certa medida, marginais do ponto de vista do teatro de operações das atuais ações anti-terroristas - pode ser considerado importante, de vez que a presença americana (econômica e política) é ainda mais relevante na América do Sul do que em outra regiões do globo.

A reação inicial do governo brasileiro, nos dias subseqüentes aos atentados, foi rápida, não apenas na mera manifestação de solidariedade, mas na significativa invocação do TIAR, o Tratado Interamericano de Assistência Recíproca, (instrumento que precedeu e inspirou formal e substantivamente o próprio tratado de Washington, que criou a OTAN) sobre a base dos mecanismos de defesa coletiva e de solidariedade hemisférica que caracterizam esse acordo assinado em Petrópolis em 1947. Em vista das circunstâncias, essa decisão foi apreciada em Washington.

O Brasil também acolheu de imediato as resoluções relevantes do Conselho de Segurança das Nações Unidas, como passou a atuar através de mecanismos informais no esforço anti-terrorista, inclusive no que se refere ao controle dos fluxos financeiros que poderiam estar servindo a organizações criminosas.

Do ponto de vista dos interesses brasileiros na agenda internacional, o 11 de setembro provocou um impacto de tipo "diversionista", no sentido em que temas de tradicional interesse para o país - comércio e desenvolvimento, entre outros tiveram que ceder considerável espaço para a questão da segurança. Essa nova situação tende a dificultar ainda mais as complexas negociações comerciais em curso nos âmbitos regional (ALCA, acordos setoriais, etc.) e multilateral (OMC pós-Doha), de vez que acentua o unilateralismo já presente na política externa americana (o qual, se mais visível nos temas de terrorismo e segurança, tende a repercutir sobre outras áreas) e relega para segundo plano qualquer questão que não possua vínculos, diretos ou indiretos, com as novas prioridades. Não foi por acaso que a Administração americana, ao procurar angariar apoio do legislativo para as negociações comerciais mencionadas acima, buscou associá-las ao programa de combate ao terrorismo.

Nesse mesmo diapasão, o efeito imediato dos ataques no Brasil foi, provavelmente, de natureza mais econômica e financeira do que propriamente política. O Brasil, assim como outros países da região, sentiu de forma mais intensa e direta os efeitos potencialmente recessivos das "conseqüências econômicas do terror”, tendo-se preparado para uma nova reversão de expectativas em relação aos fluxos globais de comércio e finanças. Passados vários meses do ocorrido, pode-se hoje especular que tais efeitos recessivos diretos não foram tão devastadores como esperado, ainda que, indiretamente, o 11 de setembro tenha contribuído para certo alheamento dos EUA em relação aos destinos econômicos 
da região (atitude visível no caso da crise da Argentina), o que não deixa de representar um problema.

É preciso, apesar de tudo, considerar que, se o 11 de setembro pôs em segundo plano temas prioritários da agenda brasileira, também resgatou, na ênfase que trouxe para a temática de segurança, aspectos importantes de política externa que, se não ocupam a pauta diária dos noticiários, são de enorme importância para o país. O Brasil, país de extensas fronteiras terrestres, que divide com regiões conturbadas como a Amazônia colombiana, não pode se dar ao luxo de negligenciar sua segurança interna e externa.

$\mathrm{Na}$ agenda interna e externa, o tema da segurança passa a adquirir um peso maior do que no passado, o que não deve ser entendido como justificativa para que objetivos prioritários (desenvolvimento econômico e social, estabilidade, comércio, abertura de mercados etc) sejam preteridos. A questão da segurança preocupa e mobiliza cada vez mais a sociedade brasileira, atingida em seu cotidiano por ações violentas e criminosas que possuem uma dimensão internacional (tráfico de drogas, por exemplo)

O novo cenário criado pelos EUA de "luta do bem contra o mal" não deixará de representar um desafio político para o Brasil, a começar pela própria concepção de um arranjo dicotômico e perigoso como o da separação entre "amigos e inimigos” da grande potência.

O Brasil certamente se alinha entre os primeiros, e está pronto a assumir sua parte de responsabilidade na adoção de medidas preventivas ao terrorismo. Sabe reconhecer, no entanto, o caráter não equivalente dos interesses imediatos de cada um, bem como as diferentes concepções que animam esses países na luta contra as redes terroristas. Nenhum dos países da América do Sul, entre eles o Brasil, desempenha ou desempenhará papel preponderante nesse grande jogo de luta contra o terrorismo mundial. Eles podem, no entanto, ajudar nesse processo, contribuindo para o reforço de sua própria segurança, assegurando a estabilidade democrática na região e dando sua contribuição para o que se poderia chamar de um "programa global” de combate ao terrorismo.

O presidente Fernando Henrique Cardoso já teve a oportunidade de expressar mais de uma vez seu entendimento do que deve ser esse "programa global”, através do tratamento de suas "fontes naturais": ausência de desenvolvimento, falta de instituições democráticas, desespero das privações sociais, sentimento de injustiça. A busca de "motivações sociais" para a ação terrorista pode parecer irrealista, ademais de um desvio do foco principal de luta contra terroristas "reais". Não deixa de ser legítimo, no entanto, procurar apaziguar, na obtenção de uma prosperidade compartilhada, os terroristas “potenciais” existentes nos muitos subúrbios miseráveis de países instáveis e estagnados .

Construir a prosperidade no mundo não é objetivo utópico. Trata-se de projeto factível, que pode ter início na adoção de medidas simples e graduais, como 
a abertura dos mercados agrícolas e a diminuição das práticas protecionistas, por exemplo, bem como por um engajamento real em políticas públicas nos países em desenvolvimento que promovam a educação e a capacitação técnica.

O Brasil dispõe de poucas alavancas de poder ou condições econômicas objetivas para impulsionar essa agenda de "prosperidade global”. Ele tem feito a sua parte, no entanto, através de um esforço em prol da abertura de mercados e da aceitação de uma interdependência mais efetiva no que se refere a questões comerciais ou normas regulatórias vinculadas ao intercâmbio global de bens, serviços, tecnologia e capitais.

Medidas específicas de combate ao terrorismo, para as quais o Brasil tem contribuído, incluem a coordenação de agências de segurança e inteligência em todo o mundo, assim como a adoção de mecanismos inibidores da utilização transfronteiriça de sistemas bancários para fins criminosos.

A ação direta contra o terrorismo passa também pela discussão de medidas de caráter preventivo e repressivo em foros mais amplos como podem ser os foros de coordenação regional e mesmo os de caráter universal como a ONU, o FMI e os órgãos diretores dos instrumentos de não-proliferação, a exemplo da Agência Internacional de Energia Atômica e da Organização para Proscrição de Armas Químicas.

Uma série de outras ações, de caráter “estrutural”, apresenta obstáculos maiores em termos de resultados imediatos. Promover a democracia e a cultura cívica, inclusive através da igualdade de gênero e da defesa dos direitos da mulher, que parecem agir como dissuasores "naturais” do comportamento radical, implica uma complexidade que não permite prejulgar resultados, de vez que não se pode exportar valores e instituições, e muito menos impor modelos políticos, ainda que democráticos, sobre outros povos e sociedades.

O Brasil não tem mais, como se sabe, um problema democrático. Ele se apresenta atualmente como uma democracia consolidada, ainda que fragilizada pela continuidade de problemas sociais persistentes. Com efeito, o problema do Brasil se situa hoje inteiramente no terreno do desenvolvimento econômico e social, o que inclui a construção de um Estado moderno e eficaz, menos propenso à corrupção de seus agentes e capaz de distribuir justiça de uma forma expedita e eficiente. O verdadeiro desafio de política interna neste Brasil do início do século XXI - o que equivaleria, no caso americano, ao terrorismo - é a injustiça social, a educação, a melhoria do sistema de saúde, o combate ao tráfico de drogas e à violência e o amparo à uma população marginalizada e entregue ao espectro de uma existência sem futuro e sem esperança.

Reside aqui o contraste maior com os objetivos imediatos dos EUA no contexto pós-11 de setembro. Uma compatibilização entre essas agendas é necessária, de maneira a que seja mantida a identidade fundamental de objetivos 
nos planos bilateral, regional e multilateral. As lideranças políticas e econômicas de ambos os países deverão encontrar um terreno comum de entente, que permita superar os poucos desencontros existentes num relacionamento amplamente positivo e reforçar ainda mais os laços de coordenação e de cooperação.

Do ponto de vista da política externa brasileira, o grande desafio, nos próximos anos, será o de identificar e definir (ou redefinir) o interesse nacional, tendo como meta a inserção do país na ordem mundial, no contexto da globalização e da era da informação, e levando em conta o unilateralismo da política externa de Washington e as novas prioridades da agenda internacional.

Na busca desse reposicionamento, o Brasil poderá fortalecer-se na medida em que assuma o papel que lhe cabe na América do Sul. A partir do momento em que o Brasil for percebido como um interlocutor interessado e ativo na região, aumentará seu peso especifico no cenário internacional. A atuação pró-ativa do Brasil nas áreas político-diplomática, econômico-comercial, financeira e de defesa deve ter como orientações principais a aproximação dos interesses comuns dos países da região, a abertura de mercados para os parceiros sul-americanos em bases preferenciais, a defesa da democracia, da segurança coletiva, do crescimento econômico e da justiça social.

Os próximos anos serão um período de significativas mudanças no cenário externo. Finda a Guerra Fria, realinhadas as grandes potências e parecendo irreversível o processo de globalização, o tema do terrorismo destaca-se como elemento central na agenda internacional ao levar a maior potência do planeta a uma importante alteração em seu modo de relacionar-se com o mundo. Nesse novo cenário, identificado ou (re)definido o interesse nacional, o País terá de se reposicionar na nova ordem mundial e no contexto da globalização, levando em conta as novas prioridades da agenda internacional e, como dado chave desse panorama mais amplo, a conduta externa dos EUA. Não se trata de adotar uma acomodação passiva ou reativa às transformações em curso, mas sim um movimento de antecipação a elas, tendo sempre presente o interesse nacional.

A agenda multilateral poderá gerar tensões com os EUA, em vista da diferença dos interesses e, muitas vezes, de enfoque em temas globais, como o meio ambiente, os direitos humanos e o próprio terrorismo. Para a política externa brasileira, o desenvolvimento econômico continuará a ser prioridade absoluta.

Nesse contexto, as negociações comerciais multilaterais, regionais e bilaterais serão preocupações permanentes e nem sempre as posições do Brasil e dos EUA serão convergentes. Nesse particular, a co-presidência Brasil-EUA das negociações da ALCA será um teste importante para o relacionamento bilateral: poderá tornar-se fator positivo de entendimento ou, ao contrário, um encontro marcado para maiores diferenças. 


\section{Notas}

1 Cf. Michael Hardt e Antonio Negri, Império (Rio de Janeiro: Record, 2001). Os autores explicam de maneira original a influência e o predomínio dos EUA no contexto do processo de globalização e identificam uma mudança radical nos conceitos que forma a base filosófica da política moderna. Procuram igualmente ressaltar a clara diferença entre o Império emergente contemporâneo e as formas hegemônicas anteriores, como a predominância européia e a expansão capitalista.

“O império só pode ser concebido como uma república universal, uma rede de poderes e contrapoderes estruturada numa arquitetura ilimitada e inclusiva. Essa expansão imperial nada tem a ver com o imperialismo, mas com esses organismos estatais projetados para a conquista, a pilhagem, o genocídio, a colonização e o racismo.” Cf. Império, op. cit. p. 185. Idem, p. 183-198.

4 Joseph Nye, “The new Rome meets the new barbarians”, The Economist, 23 março 2002.

5 Em artigo publicado na The New Yorker ( $1^{\circ}$ de abril de 2002), intitulado "The Next World Order”, Nicholas Lemann resgata as origens da atual política externa dos EUA diretrizes formuladas no início dos anos 90 (governo Bush pai) para o que seria a estratégia internacional americana pós-Guerra Fria. Por trás dessa nova estratégia, que não chegou a ser adotada em função da vitória de Clinton em 1992, estavam pessoas que hoje ocupam posições de destaque no atual governo de George W. Bush: Vice-presidente Dick Cheney, Subsecretário de Defesa Paul Wolfowitz, Chefe de Gabinete de Cheney Lewis Libby, entre outros. Essas novas diretrizes de política externa, que chegaram a ser apresentadas por George Bush em 1990 (sem grande destaque, pois o dia de apresentação coincidiu com a invasão do Kuwait pelo Iraque), preconizavam a construção de um futuro no qual os EUA se afirmariam como a única superpotência, através de ações que impedissem outras nações ou alianças de tornarem-se potências concorrentes. $\mathrm{O}$ atual presidente americano, que durante sua campanha eleitoral e nos primeiros meses da Casa Branca parecia propenso a adotar uma postura relativamente mais moderada em matéria de política externa (que tem em Colin Powell seu maior representante), foi levado, após o 11 de setembro, a aderir à "linha dura” preconizada por Cheney e Wolfowitz. O "soft power", poder de influir para que os outros passem a admirar e a procurar seguir o que os EUA desejam e buscam, complementa o "hard power”, o poderio militar. O “soft power” é crucial, mas sozinho não é suficiente: hard power e soft power serão necessários para o exercício de uma política externa bem sucedida na era da informação global, observa Joseph S. Nye em The Paradox of American Power: Why the World's Only Superpower Can't Go It Alone (New York: Oxford University Press, 2002), p. 141.

7 Em artigo publicado no New York Times de 31 de março de 2002 (“All Roads lead to D.C.”), Emily Eakin faz uma referência a uma série de artigos e livros que passam a examinar os EUA não como uma simples superpotência ou potência hegemônica, mas como um império no sentido romano ou britânico. Esse é o consenso a que chegaram alguns dos mais importantes comentaristas e acadêmicos norte-americanos por ela citados. Embora o conceito não seja aceito por muitos, as análises recentes apresentam a idéia com uma conotação positiva, nacionalista, quase ufanística. Os trabalhos mais importantes desse novo enfoque são: Why Leadership Demands a Pagan Ethos (Random House, 2001), do jornalista Robert Kaplan; o ensaio de Paul Kennedy - que havia aventado a hipótese do declínio do poderio norte-americana - "The Eagle has Landed” (Financial Times, 2-3 de fevereiro de 2002); The Case for American Empire, de Max Boot (Weekly Standard, outubro de 2001). ) e Reluctant Imperialist, comentário de Sebastian Mallaby no qual defende a idéia de que os EUA devem abandonar a relutância em assumir uma atitude hegemônica mais direta e aceitar a noção da volta da força imperia para enfrentar o desafio de um mundo mais pobre e mais violento, in Foreign Affairs, março/ abril 2002. 
$8 \quad$ L'Empire et les Nouveaux Barbares. Paris: Editions Jean-Claude Lattès, 1991)

9 A expressão foi utilizada por Richard Haas, Diretor de Planejamento Político do Departamento de Estado, in Shanker, "White House says the US is not a loner, just choosy”, mencionado por Joseph Nye, The Paradox of American Power, op. cit., p. 159.

10 Não é ocioso lembrar que o "national security interest”, o interesse da segurança nacional, é o fundamento da política externa dos EUA. Os ataques de 11 de setembro exacerbaram a aplicação da doutrina, invocada até para a defesa de posições norte-americanas nas áreas de comércio exterior, energia, agricultura e alimentos. Durante a campanha eleitoral, Condoleezza Rice e Robert Zoellick discutiram a validade dessa doutrina no período pós-Guerra Fria (ver "Promoting the National Interest”, Foreign Affairs, janeiro-fevereiro 2002).

11 Condoleezza Rice, em entrevista concebida a Nicholas Lemann, afirma que a luta contra o terrorismo e a acumulação de armas de destruição em massa por "estados irresponsáveis" definem atualmente o interesse nacional americano (The Next World Order, op. cit.). Por outro lado, documento definindo os novos parâmetros da estratégia de segurança nacional está sendo ultimado. Segundo se veiculou, seu eixo reside em uma nova interpretação do conceito de soberania - ou de seus limites. Em sua nova acepção, o conceito de soberania implicaria obrigações que, não respeitadas, poderiam dar o direito a intervenções externas. Está em gestação a doutrina Bush, pela qual cada país deve ser responsável pelo que acontece dentro de suas próprias fronteiras, inclusive no que se refere a ações terroristas. Essa doutrina reforça e dá base conceitual a outra, elaborada durante o governo George Bush pai, que previa ações no sentido de impedir a ascensão de qualquer país à condição de (segunda) superpotência concorrente (ver nota 5).

12 O combate permanente ao terrorismo pode ser visto como o substituto da luta contra o inimigo externo do tempo de maniqueísmo da Guerra fria, quando a URSS era vista como o "Império do Mal”.

13 Walter Russell Mead, senior fellow do Council on Foreign Relations de Nova York, em seu livro Special Providence: American Foreign Policy and How It Changed the World (New York: Knopf, 2001) aponta quatro visões ou escolas domésticas de política externa: a “jeffersoniana”, defensora da posição isolacionista em assuntos internacionais; a "wilsoniana", defensora do predomínio do Direito Internacional sobre os interesses dos Estados nacionais, incluindo os EUA, e do respeito aos regimes multilaterais; a "jacksoniana”, defende a ação unilateral dos EUA em defesa de seus interesses no cenário internacional, com recurso à força se preciso for; por último, a "hamiltoniana”, herdeira dos princípios condutores da política externa britânica do século XIX, de caráter essencialmente pragmático, podendo adotar posições unilaterais ou multilaterais de acordo com as circunstâncias de cada momento e as relações custo e benefício derivadas da adoção de diferentes cursos de ação.

14 Richard Haas, Diretor do Escritório de Planejamento Político do Departamento de Estado, que se pronunciou a favor do multilateralismo à la carte, em palestra no Carnegie Endowment for International Peace, em novembro de 2001, se referiu publicamente à visão do governo Bush nesse particular: "Nós já demonstramos que podemos e agiremos sozinhos quando for necessário. Um compromisso com o multilateralismo não precisa constranger nossas opções”.

15 Ver o relatório publicado no início de abril de 2002 pelo Institute for Energy and Environment Research e pelo Lawyers' Committee on Nuclear Policy, The Rule of Power or the Rule of Law?: An Assessment of U.S. Policies and Actions Regarding Security-Related Treaties, que discute a rejeição por parte dos EUA de uma série de acordos internacionais e as conseqüências disso sobre o fortalecimento das regras e das leis internacionais (New York Times, 4 de abril de 2002).

16 Em março de 2002, os EUA tornaram pública sua intenção de afastar o embaixador brasileiro José Maurício Bustani da direção da Opaq, com sede na Haia, criando um precedente nos anais do multilateralismo político ao obter apoio para, através de voto de desconfiança, removê-lo em 22 de abril de 2002. 
17 A chamada "Nuclear Posture Review", que consiste num relatório confidencial de meia centena de páginas produzido no âmbito do Pentágono e entregue ao Congresso americano em janeiro de 2002, foi revelada pela primeira vez em matéria do jornal Los Angeles Times, de 9 de março, tendo sido desde então extensivamente comentado em outros jornais e como tal objeto de crescente polêmica nos EUA e no exterior. O texto identifica as situações nas quais os EUA poderiam ser levados a utilizar armas nucleares e lista os países mais suscetíveis de estarem envolvidos nesse tipo de situação: China, Rússia, Iraque, Coréia do Norte, Irã, Líbia e Síria. A nova "postura” da administração Bush contrasta com as diretivas conhecidas da administração Clinton, que se preocupava em conter a ameaça de um ataque nuclear contra os EUA.

18 Muitas vozes, entre as quais a do Presidente Fernando Henrique Cardoso - como, por exemplo, no discurso proferido na Assembléia Nacional Francesa (30/10/01) e na abertura da LVI Assembléia-Geral das Nações Unidas (10/11/01) -, insistem em observar que essa agenda não pode ser seqüestrada pelo item “terrorismo”, mas deve dar espaço a outros problemas, em parte subjacentes ao próprio terrorismo, tais como a violência, a pobreza, a injustiça social.

19 O conceito de uni-multipolaridade está desenvolvido por Samuel Huntington, no ensaio "The Lonely Superpower”, Foreign Affairs, Março-Abril de 1999.

20 Nye, op. cit., p. 38-39, observa, por outro lado, que o mundo pós-Guerra Fria não é nem “unipolar”(conceito que exageraria o grau de hegemonia dos EUA), nem “multipolar”(conceito que induziria, equivocadamente à crença na existência de vários países com praticamente o mesmo poderio). Segundo Nye, o poder na era da informação global está distribuído entre os países de uma maneira que se assemelha a um complexo tabuleiro tridimensional: o poder militar, como já foi assinalado, é amplamente unipolar; o poder econômico é multipolar, com os EUA, a Europa e o Japão representando 2/3 do produto mundial e a China colocando-se como o quarto ator importante. Do ponto de vista econômico, os EUA não são a única potência hegemônica e têm que negociar em termos iguais, em muitas áreas, com a Europa e o Japão; nas relações transnacionais, que extravasam os limites territoriais dos países e ficam fora do controle governamental (bancos, companhias, terroristas, traficantes de drogas), o poder é vastamente disperso, não fazendo sentido falar em unipolaridade, multipolaridade ou hegemonia.

21 Segundo Nye, em The Paradox of American Power, a "Pax Americana” provavelmente terá longa duração, não somente em virtude do poderio militar incontrastado norte-americano, mas também na medida em que os EUA são a única superpotência capaz de exercer contenção estratégica (strategic restraint), tranqüilizando seus parceiros e facilitando a cooperação; op. cit., p. 17. Robert Gilpin, citado por Nye, observa que a "Pax Americana”, como a "Pax Romana” e a "Pax Britannica”, garante uma relativa paz e segurança ao sistema internacional; op. cit., p. 15.

Washington, maio de 2002

\section{Resumo}

Este artigo analisa os efeitos dos ataques terroristas de 11 de setembro para a política externa norte-americana, assim como as ressonâncias que eles produziram na ordem global. Para tanto, o presente trabalho localiza os ataques terroristas no contexto da ordem mundial, discute as ações dos EUA no imediato seguimento dos eventos, considera os efeitos dos ataques do ponto de vista da ordem internacional, examina sua interação com o processo de globalização, além 
de discutir as implicações desses fatos e processos para o Brasil e para a sua política externa.

\section{Abstract}

This article analyzes the effect of the terrorist attacks of 11 of September for the north-american foreign policy, as well as the resonances that they had produced in the global order. So, the present study locates the terrorist attacks in the context of the world-wide order, discusses the actions of U.S.A. in the immediate pursuing of the events, considers the effect of the attacks of the point of view of the international order, examines its interaction with the globalization process, besides displaying the implications of these facts and processes for Brazil and its foreign policy.

Palavras-chave: Política Internacional; Política Externa Norte-americana; Terrorismo; Ordem Internacional; Política Externa Brasileira.

Key words: Internacional Polítics; North-American Foreign Policy; Terrorism; International Order; Brazilian Foreign Policy. 